\title{
Characteristics of enterotoxin distribution, hemolysis, lecithinase, and starch hydrolysis of Bacillus cereus isolated from infant formulas and ready-to-eat foods
}

\author{
Ji-Yeon Hwang and Jong-Hyun Park ${ }^{1}$ \\ Department of Food Science and Biotechnology, Gachon University, Sungnam 461-701, Republic of Korea
}

\begin{abstract}
Bacillus cereus is a ubiquitous environmental microbe implicated as a main cause of food poisoning with various symptoms, depending on the strain type and the isolation source. In this study, the potential virulence factors and biochemical properties of $B$. cereus isolated from infant formulas and ready-to-eat (RTE) foods were analyzed and compared. A total of 347 B. cereus strains were isolated and identified from 687 infant food formulas and RTE food samples. All the isolates had one or more enterotoxin genes, and one-half of the strains had all 3 enterotoxin genes ( $h b l$, nhe, and $c y t K)$ that are involved in food poisoning in humans. Here, all the 3 genes were detected in $50 \%$ of the B. cereus isolates from RTE foods and only $14 \%$ of the isolates were identified from infant formulas. The latter harbored low $c y t K$ and $b c e T$, and very low $h b l$ genes. Most $B$. cereus isolates possessed the hemolysis gene, but not the ces gene. The infant formula isolates showed stronger hemolysis activity than the other isolates. In addition, $26 \%$ of the total isolates showed low lecithinase activities and $10 \%$ showed high lecithinase activities. A greater number of isolates from the infant formula showed high lecithinase activity than those from the RTE foods. Approximately $83 \%$ of the isolates were positive and $17 \%$ were negative for starch hydrolysis. Over $90 \%$ of the RTE food isolates and only $35 \%$ of the infant formula isolates were positive for starch hydrolysis. However, all the strains possessed nhe, but their harboring patterns of $h b l$ and $c y t K$ were significantly different. Most starch-hydrolyzing strains possessed $h b l$, but only $23 \%$ nonstarch-hydrolyzing isolates possessed this gene. Moreover, very low nonstarch hydrolyzing strains harbored cytK. Most nonstarch-hydrolyzing isolates showed high lecithinase and strong hemolysis activities, and very low $h b l$ and $c y t K$ harboring. In summary, most infant formula isolates showed stronger hemolysis and higher lecithinase activities with lower
\end{abstract}

Received October 30, 2014.

Accepted December 2, 2014.

${ }^{1}$ Corresponding author: p5062@gachon.ac.kr frequency of harboring $h b l$ and $c y t K$ and lower starch hydrolysis compared with RTE food isolates.

Key words: Bacillus cereus, enterotoxin gene, lecithinase activity, starch hydrolysis, infant formula

\section{INTRODUCTION}

Bacillus cereus is widely distributed in nature as a soil microorganism, and consumption of food contaminated with $>10^{5}$ cells/g of $B$. cereus may cause food poisoning. In particular, B. cereus strains form spores that facilitate their survival for a long period in dry foods even after heat treatment, owing to the thermal resistance offered by the spore form, thereby easily causing food poisoning (Goepfert et al., 1972; Kramer and Gilbert, 1989).

The clinical manifestations of $B$. cereus food poisoning are known to be caused by activities of exotoxins, lecithinase, protease, and hemolysis (Turnbull et al., 1979). In particular, B. cereus strains produce diverse types of toxins that cause food poisoning of the diarrheal or emetic type (Agata et al., 1995; Granum et al., 1996; Lund and Granum, 1997; Ombui et al., 1997; Schoeni and Wong, 2005). Bacillus cereus strains produce at least 5 different enterotoxins, excluding the emetic toxin. Hemolysin BL (HBL) and nonhemolytic enterotoxin (Nhe) are composed of 3 proteins, whereas EntFM, CytK, and BceT are composed of only one protein each (Granum and Lund, 1997; Hansen et al., 2003). The HBL, Nhe, and CytK toxins are implicated in food poisoning in humans, whereas HBL and Nhe toxins have been implicated in exerting cytotoxic and hemolytic activities. The CytK toxin was reported to cause severe symptoms and bloody diarrhea in a recent outbreak (Lund et al., 2000).

The second type of $B$. cereus toxin discovered in the 1970s was associated with the consumption of fried rice. This toxin caused food poisoning of the emetic type and was referred to as cereulide; it was a small, cyclic, heat-stable peptide (Marahiel et al., 1997). Because of the lack of a convenient method for detecting the emetic toxin, the role of $B$. cereus strains as the causative agents in emetic food poisoning remains underestimat- 
ed. Emetic toxin-producing B. cereus has been reported to neither produce diarrheal toxin nor hydrolyze starch (Ehling-Schulz et al., 2005; Pirhonen et al., 2005).

Besides the enterotoxins and emetic toxin, B. cereus produces several other virulence factors that damage the cell membrane. Several types of lecithinase, sphingomyelinase, and cereolysin are known to possess thiol group-activated hemolysis activity and have been associated with outbreaks (Brillard and Lereclus, 2007). Lecithinase secreted by B. cereus is similar to the $\alpha$-toxin of Clostridium perfringens and has weak toxicity (Beecher et al., 2000). Lecithinase may play a synergistic role in dissolving red blood cells with sphingomyelinase.

Although B. cereus is known to contaminate a variety of foods as a soil microorganism, diarrheal poisoning has not been frequently reported. In addition, in the reported cases, the ability to cause diarrheal outbreaks has been attributed to several different types of strains (Guinebretière et al., 2002). According to the type of disease characterized in each country, emetic poisoning has been reported more than 10 times as frequently as diarrhea in Japan, but diarrheal poisoning has been reported mostly in Europe and North America. The difference in the occurrences of diarrheal poisoning in different countries depends on the differences in food consumption habits (Rhodehamel and Harmon, 1995; Granum and Baird-Parker, 2000). It is therefore necessary to study the profiles of these virulence factors because they may differ in $B$. cereus toxicity according to the type of contaminated food considered.

Recently, due to changes in dietary habits, the production of ready-to-eat (RTE) foods, refrigerated foods, and retort pouch foods has also increased. Although RTE foods offer the advantage of saving cooking time, the lack of heating and cooking processes involved in their consumption makes them vulnerable to contamination by food-poisoning bacteria. After first identifying B. cereus as a foodborne pathogen in Norway in 1949 , its outbreaks have been reported to be related to the consumption of fried rice, pasta, cooked vegetables, salad, and sprouts in several countries (Lindqvist et al., 2000; Sewell and Farber, 2001; Sivapalasingam et al., 2004). Infant formula is a milk-based nonsterile food product fed to infants for whom breastfeeding is difficult and for infants with incompletely developed immune systems. A possibility of contamination of infant formula by opportunistic pathogens always exists, albeit with a low probability. The opportunistic pathogens in infant formula are classified into categories $\mathrm{A}, \mathrm{B}$, and $\mathrm{C}$, with reference to the Food and Agricultural Organization (FAO)/World Health Organization (WHO) report (FAO/WHO, 2004). In fact, it has been reported that milk and milk-based products have a very high prevalence of $B$. cereus (Reyes et al., 2007; Bartoszewicz et al., 2008; Hwang et al., 2008). There is a paucity of reports regarding $B$. cereus (category $\mathrm{C}$ pathogen) contamination of infant formula; therefore, it is important to analyze the relative hazard of a $B$. cereus-contaminated infant formula.

Therefore, in this study, the characteristics of the virulence factors and the biochemical characteristics of $B$. cereus from infant formula and RTE foods were analyzed.

\section{MATERIALS AND METHODS}

\section{Isolation Samples}

A total of 687 samples of powdered infant formula and RTE foods such as produce, cup-drinks sold by street vendors, instant cereals (Sunsik), sushi, and steamed rice rolled in Gim (Gimbap) in the market were collected for isolating $B$. cereus. The samples were collected during 4 intermittent survey research projects from the 2002 to 2007. Ninety-nine powdered infant formulas were reinforced with starch, oil, minerals, and vitamins in addition to the main cow milk component for infants aged $<1 \mathrm{yr}$. These formulas were purchased from different production batches of various brands from local manufacturers as well as imported brands available at the time of collection. In addition, 193 samples of fresh food items such as salad, sprouts, fruits, and vegetables in RTE form were purchased from local markets. Moreover, 234 samples of complex foods such as Sunsik, Gimbap, and sushi purchased from local markets, and 161 cup-drinks were purchased at vending machines in the streets.

\section{Isolation and Identification of B. cereus}

Isolation and identification of $B$. cereus were carried out according to the conventional and modified method of Food Code established by the Korea Food and Drug Administration. The samples were homogenized with sterile buffered peptone water (Oxoid, Basingstoke, UK) and inoculated on mannitol-egg yolk-polymyxin B agar (MYP; Difco, Detroit, MI); the inoculated media were incubated at $36^{\circ} \mathrm{C}$ for $24 \mathrm{~h}$. Following incubation, pink colonies with opaque halos were selected and subcultured at $36^{\circ} \mathrm{C}$ for $24 \mathrm{~h}$ on tryptic soy agar (TSA; Difco). The isolates grown on TSA were further confirmed on MYP agar and subjected to PCR using the primer pair $\mathrm{BC} 1 / \mathrm{BC} 2 \mathrm{r}$, and classified as part of the B. cereus group (Yamada et al., 1999). Bacillus cereus strains were distinguished from Bacillus thuringiensis strains by PCR with the BT1/BT2r primer pair targeting the gyrB gene (Yamada et al., 1999). Finally, once 
more the isolates were confirmed as $B$. cereus by PCR with the K3/K5 primer pair targeting the cry gene on the basis that $B$. cereus does not produce crystal toxin, whereas B. thuringiensis does (Kuo and Chak, 1996). Bacillus cereus KCCM 40935, B. cereus KCTC 1094, B. thuringiensis KCCM 11428, and B. thuringiensis KCTC 3452 type strains were used as a reference enterotoxin control for PCR. To prepare DNA template, cells were collected from 1 loop of colony on TSA incubated for $24 \mathrm{~h}$. The pellet was washed twice with $1 \mathrm{~mL}$ of sterile distilled water after centrifugation at $9,810 \times g$ for 5 min at $4^{\circ} \mathrm{C}$ and boiled for $5 \mathrm{~min}$. The supernatants were used as DNA templates. Biochemical tests were performed after sufficiently activating B. cereus on TSA. The biochemical tests, including Gram staining, glucose fermentation, Voges-Proskauer reaction, nitrate reduction, and motility, were performed as per the Food and Drug Administration Bacterial Analytical Manual methods (Rhodehamel and Harmon, 1995).

\section{Detection of Exotoxin Genes}

The following $B$. cereus exotoxin genes were detected and confirmed by PCR: HBL, Nhe, cytotoxin K, enterotoxin $\mathrm{T}$, enterotoxin FM, and emetic toxin genes. To detect the $h b l$ gene, PCR was performed with the HBLC-N/HBLC-C primer pair targeting the $h b l C$ component gene. The $h b l C$-nonharboring $B$. cereus were further subjected to PCR with the HBLD-N/HBLD-C and HBLA1/HBLA2 primers targeting $h b l D$ and $h b l A$ component genes, respectively (Rowan et al., 2003). To detect nhe, PCR was performed with the nhe344S/ nheB843A primer pair targeting the nheA component gene. When nheA was not detected, the NBF/NBR and $\mathrm{NCF} / \mathrm{NCR}$ primers were used to target nheB and nhe $C$ (Ghelardi et al., 2002; Guinebretière et al., 2002). To detect $c y t K$, PCR was performed with the F2/R7 primer pair targeting cytK (Lund et al., 2000). The ETF/ETR primer pair was used to detect becT of enterotoxin $\mathrm{T}$, and the ENTA/ENTB primer was used to detect entFM of enterotoxin FM (Asano et al., 1997; Ghelardi et al., 2002). For detecting the emetic toxin gene, PCR was performed with the CesF1/CesR2 primer pair targeting ces (Ehling-Schulz et al., 2005).

\section{Hemolysis and Lecithinase Activity Analyses}

Bacillus cereus was incubated for $24 \mathrm{~h}$ at $36^{\circ} \mathrm{C}$ on TSA with sheep blood. After incubation, the diameter of the hemolytic zone formed was measured to determine the extent of hemolysis by using calipers (Anyi Instrument, Guilin, China). For determining the lecithinase activity, $B$. cereus was inoculated in B. cereus-selective MYP agar and incubated for $21 \mathrm{~h}$ at $36^{\circ} \mathrm{C}$, followed by mea- surement of the length of the opaque halo formed on the media.

\section{Starch Hydrolysis}

To confirm the starch hydrolysis activity, B. cereus isolates were grown on nutrient agar (Oxoid) containing $1 \%$ soluble starch and incubated at $30^{\circ} \mathrm{C}$ for 24 h. Hydrolysis was observed as formation of a colorless zone around a $B$. cereus colony after flooding the plate with Gram's iodine, followed by measurement of the length of the zone using calipers.

\section{RESULTS AND DISCUSSION}

\section{Isolation and Identification of Foodborne B. cereus}

In total, $507 \mathrm{~B}$. cereus group isolates were isolated from 687 samples of various food items by culturing on selective MYP medium, followed by identification by biochemical tests and $\mathrm{PCR}$ with the $\mathrm{BC} 1 / \mathrm{Bc} 2 \mathrm{r}$ primer pair. Of the 507 isolates, 165 were isolated from 99 powdered infant formulas, 144 from fresh foods, and 198 from complex foods (Table 1).

Biochemical tests were performed to differentiate the B. cereus group as per Bacterial Analytical Manual methods, such as lecithinase activity, motility, nitrate reduction, Voges-Proskauer, $\beta$-hemolysis, and anaerobic utilization of glucose. The biochemical characteristics of the isolates varied widely, except that all showed positive reactions for lecithinase activity and anaerobic utilization of glucose (data not shown). In particular, approximately $80 \%$ of the total isolates showed motility and $93 \%$ showed $\beta$-hemolysis. Typical B. cereus showed positive reactions for all of the above-mentioned tests (Rhodehamel and Harmon, 1995). It has been also reported that $B$. cereus and $B$. thuringiensis of the $B$. cereus group can be distinguished by hemolytic activity, motility in a selective medium, and crystal toxin protein from Bacillus mycoides and Bacillus anthracis (Lechner et al., 1998; Nakamura, 1998; Granum and Baird-Parker, 2000). However, several of the B. cereus isolates in this study showed atypical biochemical characteristics not reported earlier. Therefore, it was vital to perform PCR targeting specific genes for the $B$. cereus group to differentiate and identify the isolates.

To distinguish $B$. cereus from B. thuringiensis with similar phenotypic and genotypic characteristics, all 507 isolates of the $B$. cereus group were subjected to PCR with the BT1/BT2r primer pair targeting $\operatorname{gyr} B$, which finally identified $379 B$. cereus strains. The selected $B$. cereus strains were subjected to PCR with the K3/ K5 primer pair targeting cry because it is expressed as crystal toxin by $B$. thuringiensis only. From among the 
Table 1. Isolation and identification of Bacillus cereus from infant formula and ready-to-eat (RTE) food collected from the local area

\begin{tabular}{lcccc}
\hline & & \multicolumn{2}{c}{$\begin{array}{c}\text { No. of Bacillus strains identified } \\
\text { with gyrB and } \text { cry PCR primers }\end{array}$} \\
\cline { 3 - 5 } $\begin{array}{l}\text { Food sample } \\
\text { (no. of samples) }\end{array}$ & $\begin{array}{c}\text { No. of B. cereus } \\
\text { group isolates }\end{array}$ & $\begin{array}{c}\text { B. cereus } \\
\text { Infant formulas, powdered (99) }\end{array}$ & B. thuringiensis & Others \\
\hline RTE, fresh foods (193) & 165 & 69 & 96 & 0 \\
Salad (25) & 144 & 115 & 28 & 1 \\
Sprout (65) & 38 & 23 & 15 & 0 \\
Produce (43) & 63 & 59 & 4 & 0 \\
RTE, complex foods (395) & 43 & 163 & 9 & 1 \\
Street-vendor cup drink (161) & 58 & 45 & 28 & 4 \\
Sunsik, powdered grain (94) & 86 & 69 & 14 & 3 \\
Sushi (105) & 29 & 27 & 2 & 0 \\
Gimbap (35) & 27 & 22 & 5 & 0 \\
Total (687) & 507 & 347 & 152 & 8 \\
\hline
\end{tabular}

379 B. cereus strains tested, 32 strains were confirmed to be $B$. thuringiensis harboring cry. Finally, 347 B. cereus, 152 B. thuringiensis, and 8 Bacillus spp. were identified from among 507 isolates belonging to the $B$. cereus group. Thus, the isolation ratio of 347 B. cereus strains from 687 food samples was $50 \%$. The prevalence of the isolates from the food items of dried milk product, rice, ground roasted coffee, and German infant formula was similar to this ratio reported here (Becker et al., 1994; Shaheen et al., 2006; Reyes et al., 2007; Ankolekar et al., 2009; Chaves et al., 2012). However, the prevalence of the isolates for the weaning cereal was found to be less than the reported value (Kunene et al., 1999). In this study, $80 \%$ of the B. cereus group isolated from RTE foods were B. cereus, but only $40 \%$ of the $B$. cereus group from infant formulas were $B$. cereus.

\section{Exotoxin Gene Distribution of B. cereus}

To determine the distribution of exotoxins, $347 \mathrm{~B}$. cereus isolates were analyzed for 1 emetic toxin gene, $c e s$, and 5 enterotoxin genes, hbl, nhe, cytK, bceT, and entFM, by PCR with the primers listed in Table 2 . It has been reported that some isolates may cause poisoning with only 1 or 2 genes from among $h b l$ or nhe component genes (Hansen and Hendriksen, 2001; Ngamwongsatit et al., 2008). Therefore, the presence of any one of the $h b l C, h b l D$, and $h b l B$ component genes coding for lytic component $\mathrm{L}_{2}, \mathrm{~L}_{1}$, and binding component $\mathrm{B}$ of HBL toxin was considered positive for $h b l$. In addition, the presence of any one of the nheA, $n h e B$, and nhe $C$ component genes coding for Nhe toxin was considered positive for nhe. Those were due to the reports that some isolates might cause poisoning with only 1 or 2 genes among $h b l$ component genes or nhe component genes (Hansen and Hendriksen, 2001; Ngamwongsatit et al., 2008).
Among the total 347 B. cereus isolates, 290 (84\%) harbored $h b l$ (Table 3). More than $95 \%$ of the strains isolated from RTE foods possessed $h b l$ and approximately $30 \%$ of isolates from infant formulas possessed $h b l$. Some previous studies have reported that 60 to $90 \%$ of the strains isolated from various food items harbored hbl (Ankolekar et al., 2009; Chaves et al., 2012; Chon et al., 2012). Here, although the RTE food isolates complied with these earlier reports, unpredictably, only $30 \%$ of the infant formula isolates possessed $h b l$. In addition, the isolates from all food samples harbored nhe. These results are consistent with the available results of B. cereus harboring nhe (Guinebretière et al., 2002; Ankolekar et al., 2009; Chaves et al., 2012; Chon et al., 2012). The CytK toxin is known to induce diarrhea similarly to the HBL and Nhe toxins (Lund and Granum, 1997). Among the isolates in this study, 167 strains $(48 \%)$ possessed cytK, but its prevalence was low compared with that of other enterotoxin genes; this observation is consistent with those of earlier studies reporting 45 to $80 \%$ isolates from other foods harboring cytK (Chon et al., 2012; Lee et al., 2012). However, the prevalence of $c y t K$ in the infant formula isolates was less than one-half of that in the RTE food isolates. Similar to other studies, in this study, $277(80 \%)$ and $323(93 \%)$ of isolates possessed the genes of enterotoxin $\mathrm{T}$ and enterotoxin FM, respectively, that may have the same biological activities as HBL and Nhe, although evidence for their contribution to food poisoning is unclear. Among the infant formula isolates, the entFM harboring ratio was similar to that reported previously, but the bce $T$ harboring ratio was $36 \%$ and thus very low. However, the emetic toxin gene causing emetic syndrome was not detected in any of the $347 \mathrm{~B}$. cereus strains tested (data not shown). Thus, the distribution pattern of the 5 enterotoxin genes of $B$. cereus from RTE foods was similar to those reported earlier. How- 
Table 2. Oligonucleotide primers for detecting members of the Bacillus cereus group

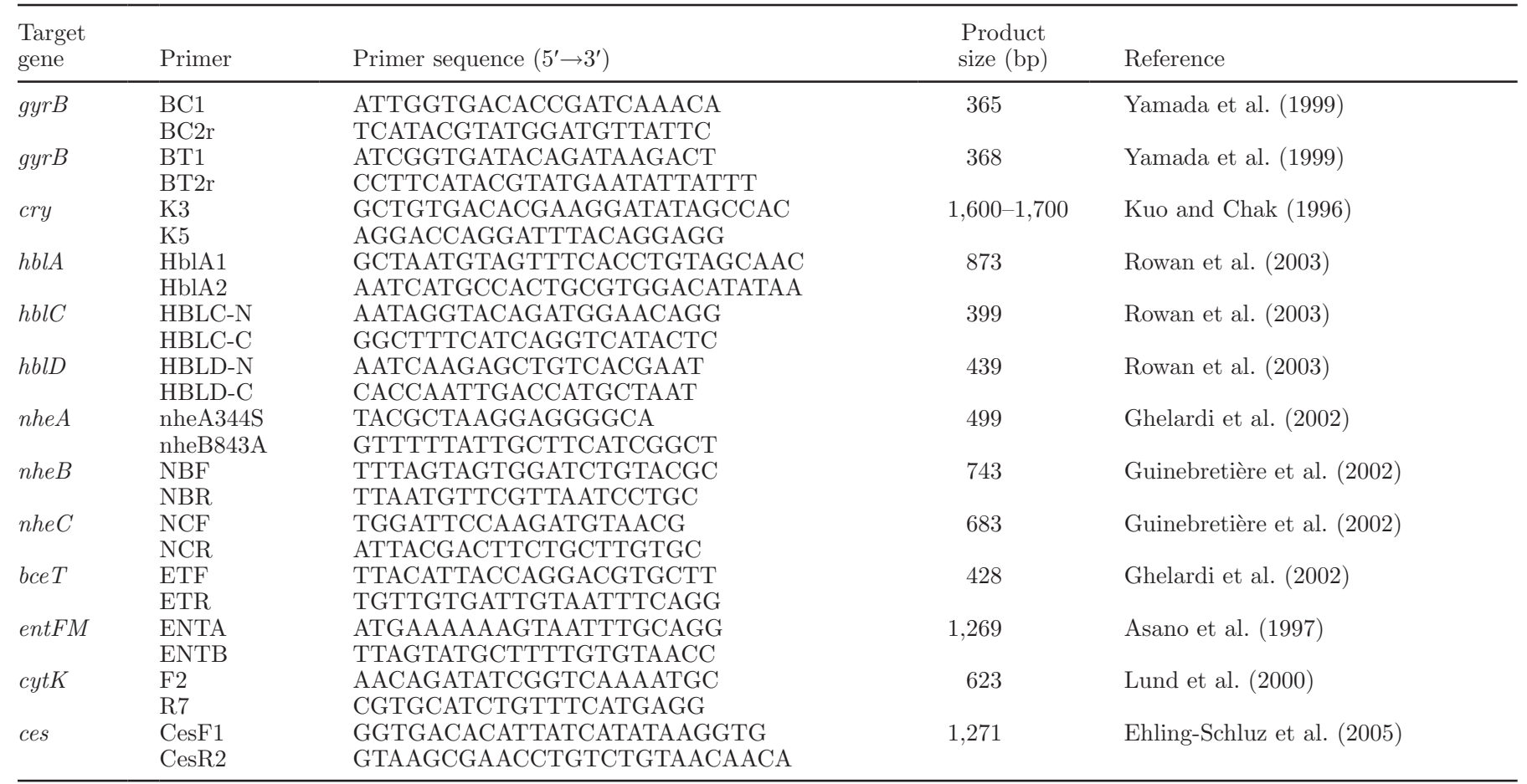

ever, interestingly, the infant formula isolates harbored lower $c y t K$ and $b c e T$, and very low $h b l$.

All the isolates in this study possessed one or more of the enterotoxin genes, and $43 \%$ of the total isolates possessed all 5 diarrheal enterotoxin genes. In particular, $46 \%$ of the total isolates possessed all 3 enterotoxin genes, $h b l$, nhe, and cytK, which reportedly cause food poisoning in humans. Here, $50 \%$ of the RTE food isolates possessed the 3 genes, whereas only $14 \%$ of the infant formula isolates possessed these genes. Very low $B$. cereus poisoning has been reported in milk and dairy products, unlike the actual prevalence of $\mathrm{B}$. cereus, probably because milk is not suitable for toxin production (Becker et al., 1994; Reyes et al., 2007). Productions of HBL and NHE protein for some isolates were confirmed using commercial toxin detection kit (data not shown). However, the genes might not be expressed in some culture conditions (Rowan and Anderson, 1997). This study thus suggests that the low outbreak of $B$. cereus poisoning due to infant formula consumption can be attributed to $B$. cereus containing fewer enterotoxin genes.

\section{Characteristics of Hemolysis and Lecithinase for $B$. cereus Isolates}

In total, 93 of the 347 isolates $(27 \%)$ showed weak or no hemolysis and $62(18 \%)$ showed strong hemolysis (Table 4). The infant formula isolates showed a stronger level of hemolysis than the other isolates. It has been reported that $95 \%$ of the 133 B. cereus isolates from honey demonstrated hemolysis activity (López and Alippi, 2007), and the isolates causing food poisoning showed very strong hemolysis (Stec, 1990; Pirhonen

Table 3. Distribution of enterotoxin genes of Bacillus cereus isolates from infant formulas and ready-to-eat (RTE) foods

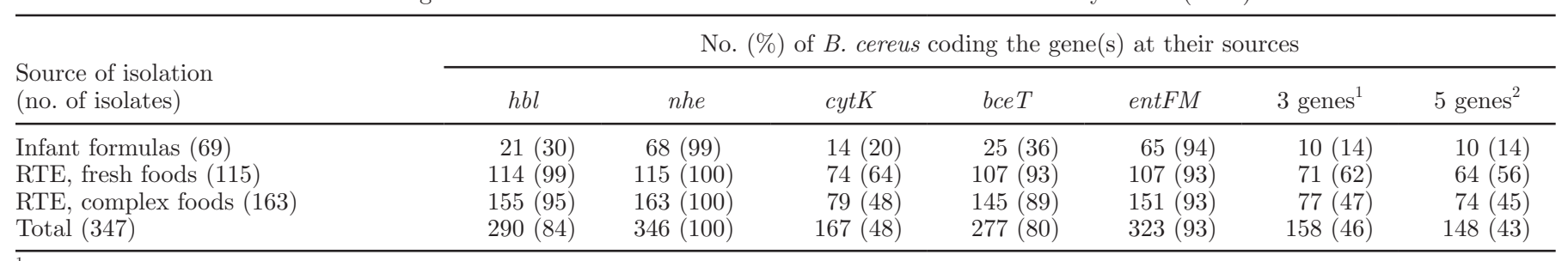

${ }^{1}$ Three genes $=h b l+n h e+c y t K$.

${ }^{2}$ Five genes $=h b l+n h e+c y t K+b c e T+e n t F M$. 
Table 4. Distribution of Bacillus cereus showing hemolysis isolated from infant formulas and ready-to-eat (RTE) foods

\begin{tabular}{lccc}
\hline & \multicolumn{2}{c}{ No. (\%) of B. cereus showing hemolysis ${ }^{1}$} \\
\cline { 2 - 4 } $\begin{array}{l}\text { Source of isolation } \\
\text { (no. of isolates) }\end{array}$ & Strong & Intermediate & Weak/none \\
\hline Infant formulas (69) & $21(30)$ & $37(54)$ & $11(16)$ \\
RTE, fresh foods (115) & $20(17)$ & $60(52)$ & $34(30)$ \\
RTE, complex foods (163) & $62(13)$ & $95(58)$ & $48(29)$ \\
Total (347) & $62(18)$ & $192(55)$ & $93(27)$ \\
\hline 1'The hemolysis activity was measured as the length of the zone from the edge of a colony as follows: $>3$-mm \\
length = strong; 1.5-3-mm length = intermediate; and <1.5-mm length = weak/none after 24-h incubation \\
in sheep blood agar.
\end{tabular}

et al., 2005). In general, most B. cereus isolated from various food items show hemolysis. According to another report, all 60 of the 222 B. cereus isolates showing strong hemolysis did not produce emetic toxin, but 77 isolates showing weak or no hemolysis produced cereulide (Andersson et al., 2004). However, most of the newly isolated $B$. cereus in this study showed hemolytic activity and did not possess ces. The hemolytic activity of infant formula isolates was found to be a little stronger than that of the other isolates.

In total, 91 of the $347 \mathrm{~B}$. cereus isolates (26\%) showed low lecithinase activities, and 35 isolates (10\%) showed high lecithinase activities (Table 5). Among the isolates showing low activity, almost all of the strains were isolated from RTE fresh foods and complex foods and only 4 strains were isolated from infant formula, constituting $6 \%$ of all isolates from the infant formulas. In contrast, among the isolates showing high lecithinase activity, 18 were isolated from RTE foods and 17 were obtained from infant formula, amounting to $25 \%$ of all isolates from infant formulas. Thus, the ratio of isolates showing high lecithinase activity was higher for infant formulas than for other foods. Bacillus cereus from milk-based products such as infant formula seemed to have higher lecithinase activity because they could use the lecithin component of the milk fat globule for nutrition. In Table 6, 43\% of the isolates with high lecithinase activity showed strong hemolytic activity and $47 \%$ of the isolates with low lecithinase activity showed weak or no hemolytic activity. These results suggest that lecithinase may somehow be involved in hemolysis, even if it is not strictly correlated, as also observed by other studies (Stec, 1990; Beecher et al., 2000). In fact, lecithinase has been suggested as a putative virulence factor in systemic infection with enterotoxin (Drobniewski, 1993). Isolates with low lecithinase activity were also found to harbor $h b l$ and $c y t K$ at about a 2-times greater frequency than isolates with high lecithinase activities. Thus, the infant formula isolates showed stronger hemolysis and higher lecithinase activities with lower frequency of harboring of $h b l$ and cytK compared with the other isolates.

\section{Starch Hydrolysis and Enterotoxin Gene Profile of the Isolates}

The starch hydrolysis characteristics of the isolates were also analyzed as they have been proposed as an indicator that characterizes diarrheal and emetic poisoning by $B$. cereus. In total, 287 of the 347 isolates $(83 \%)$ were positive for starch hydrolysis and 60 isolates $(17 \%)$ were negative for starch hydrolysis in Table 7. More than $90 \%$ of the RTE food isolates were positive for starch hydrolysis; however, only $35 \%$ of the infant formula isolates were positive for starch hydrolysis. In addition, approximately $45 \mathrm{~B}$. cereus isolates

Table 5. Distribution of Bacillus cereus showing lecithinase activity from infant formulas and ready-to-eat (RTE) foods

\begin{tabular}{|c|c|c|c|}
\hline \multirow[b]{2}{*}{$\begin{array}{l}\text { Source of isolation } \\
\text { (no. of isolates) }\end{array}$} & \multicolumn{3}{|c|}{ No. $(\%)$ of B. cereus producing lecithinase on $\mathrm{MYP}^{1}$ agar } \\
\hline & High activity $^{2}$ & $\begin{array}{l}\text { Intermediate } \\
\text { activity }\end{array}$ & Low activity \\
\hline Infant formulas (69) & $17(25)$ & $48(69)$ & $4(6)$ \\
\hline RTE, fresh foods (115) & $8(7)$ & $73(63)$ & $34(30)$ \\
\hline RTE, complex foods (163) & $10(5)$ & $100(61)$ & $53(33)$ \\
\hline Total $(347)$ & $35(10)$ & $221(64)$ & $91(26)$ \\
\hline
\end{tabular}


Table 6. Relationship of lecithinase-producing Bacillus cereus from infant formulas and ready-to-eat (RTE) foods showing hemolysis and harboring enterotoxin genes $h b l$, nhe, and $c y t K$

\begin{tabular}{lcc}
\hline & \multicolumn{2}{c}{$\begin{array}{c}\text { No. (\%) of lecithinase- } \\
\text { producing B. cereus }\end{array}$} \\
\cline { 2 - 3 } $\begin{array}{l}\text { Virulence } \\
\text { factor }\end{array}$ & High $(\mathrm{n}=35)$ & Low $(\mathrm{n}=88)$ \\
\hline Hemolysis & & \\
$\quad$ Strong & $15(43)$ & $52(6)$ \\
Intermediate & $18(51)$ & $41(47)$ \\
Weak/none & $2(6)$ & $84(95)$ \\
Enterotoxin gene & & $88(100)$ \\
$h b l$ & $19(54)$ & $57(65)$ \\
$n h e$ & $35(99)$ & \\
cytK & $8(23)$ & \\
\hline
\end{tabular}

(65\%) from infant formula samples were negative for starch hydrolysis, which is twice as many as the number of positive strains. The strains negative for starch hydrolysis did not possess ces. The starch hydrolysis test has been proposed as an indicator to identify the emetic type of B. cereus (Ehling-Schulz et al., 2005; Pirhonen et al., 2005). However, some studies have reported that the characteristic of starch hydrolysis is not directly related to the production of emetic toxin (Rahmati and Labbe, 2008; Ankolekar et al., 2009). According to these results, the starch hydrolysis activity did not seem to be related directly to the secretion of emetic toxin.

Nonstarch-hydrolyzing $B$. cereus strains were analyzed to assess the relationship of starch hydrolysis with other virulence factors in Table 8 . The 287 strains positive for starch hydrolysis showed high to low lecithinase activity. Thirty percent of the starchhydrolyzing isolates showed low lecithinase activity. In clear contrast, all of the 60 nonstarch-hydrolyzing strains showed more than the intermediate level of lecithinase activity. Therefore, nonstarch-hydrolyzing
Table 7. Starch hydrolysis of Bacillus cereus isolated from infant formulas and ready-to-eat (RTE) foods on nutrient agar containing starch

\begin{tabular}{lcc}
\hline & \multicolumn{2}{c}{$\begin{array}{c}\text { No. (\%) of starch-hydrolyzing } \\
\text { B. cereus } \text { isolates }\end{array}$} \\
\cline { 2 - 3 } $\begin{array}{l}\text { Source of isolation } \\
\text { (no. of B. cereus) }\end{array}$ & Hydrolysis & Nonhydrolysis \\
\hline Infant formulas (69) & $24(35)$ & $45(65)$ \\
RTE, fresh foods (115) & $113(98)$ & $2(2)$ \\
RTE, complex foods (163) & $150(92)$ & $13(8)$ \\
Total (347) & $287(83)$ & $60(17)$ \\
\hline
\end{tabular}

strains had a tendency to have the lecithinase enzyme. Here all the strains showing the high lecithinase activity in the group of nonstarch hydrolysis were isolated from infant formula (data not shown). However, no significant correlation was observed between hemolysis and starch hydrolysis. Regarding enterotoxin genes, all isolates harbored nhe, but the harboring pattern for $h b l$ and cytK was significantly different. In particular, only $23 \%$ of the nonstarch-hydrolyzing strains possessed $h b l$, whereas most of the starch-hydrolyzing strains possessed the gene. In addition, very few of the nonstarch-hydrolyzing strains harbored cytK. Bacillus cereus harboring enterotoxin genes was reported to stimulate the production of diarrheal enterotoxins by using hydrolysates such as glucose and maltodextrin from starch hydrolysis (Rowan and Anderson, 1997). Therefore, we can infer that starch hydrolysis for $B$. cereus is required for good expression of the enterotoxin genes such as $h b l$ and $c y t K$.

In conclusion, nonstarch-hydrolyzing $B$. cereus isolates were presented in infant formula at a high frequency, and these isolates showed high lecithinase activity and a low frequency of $h b l$ and $c y t K$, suggesting that these genes might not be required in a milk-based environment.

Table 8. Relationship of starch-hydrolyzing Bacillus cereus from powdered infant formulas and ready-to-eat (RTE) foods showing lecithinase and hemolysis activities and harboring enterotoxin genes $h b l$, nhe, and $c y t K$

\begin{tabular}{lcc}
\hline & \multicolumn{2}{c}{ No. $(\%)$ of starch-hydrolyzing $B$. cereus isolates } \\
\cline { 2 - 3 } Virulence factor & Hydrolysis $(\mathrm{n}=287)$ & Nonhydrolysis $(\mathrm{n}=60)$ \\
\hline Lecithinase activity & $21(7)$ & $14(23)$ \\
High & $178(62)$ & $46(77)$ \\
Intermediate & $88(31)$ & 0 \\
Low & $50(17)$ & $12(20)$ \\
Hemolysis & $152(53)$ & $39(65)$ \\
Strong & $85(30)$ & $9(15)$ \\
Intermediate & & $14(23)$ \\
Weak/none & $276(96)$ & $60(100)$ \\
Enterotoxin gene & $287(100)$ & $3(5)$ \\
nhe & $166(58)$ & \\
$c y t K$ & &
\end{tabular}




\section{ACKNOWLEDGMENTS}

Financial support for this work was provided by the Korean Food and Drug Administration (Seoul, Republic of Korea; Grant-50, 07052FoodSafety055, S-0602-2-SES-084-4-T) and National Veterinary Research and Quarantine Service (Anyang, Republic of Korea; ZFS03-2007-07-01).

\section{REFERENCES}

Agata, N., M. Ohta, Y. Arakawa, and M. Mori. 1995. The bceT gene of Bacillus cereus encodes and enterotoxic protein. Microbiology 141:983-988

Andersson, M. A., E. L. Jääskeläinen, R. Shaheen, T. Pirhonen, L. M. Wijnands, and M. S. Salkinoja-Salonen. 2004. Sperm bioassay for rapid detection of cereulide-producing Bacillus cereus in food and related environments. Int. J. Food Microbiol. 94:175-183.

Ankolekar, C., T. Rahmati, and R. C. Labbe. 2009. Detection of toxigenic Bacillus cereus and Bacillus thuringiensis spores in U.S. rice. Int. J. Food Microbiol. 128:460-466.

Asano, S., Y. Nukumizu, and H. Bando. 1997. Cloning of novel enterotoxin genes from Bacillus cereus and Bacillus thuringiensis. Appl. Environ. Microbiol. 63:1054-1057.

Bartoszewicz, M., B. M. Hansen, and I. Swiecicka. 2008. The members of the Bacillus cereus group are commonly present contaminants of fresh and heat-treated milk. Food Microbiol. 25:588-596.

Becker, H., G. Schaller, V. W. Wolfgang, and G. Terplan. 1994. Bacillus cereus in infant foods and dried milk products. Int. J. Food Microbiol. 23:1-15.

Beecher, D. J., T. W. Olsen, E. B. Somers, and A. C. Wong. 2000. Evidence for contribution of tripartite hemolysin BL, phosphatidylcholine-preferring phospholipase $\mathrm{C}$, and collagenase to virulence of Bacillus cereus endophthalmitis. Infect. Immun. 68:5269-5276.

Brillard, J., and D. Lereclus. 2007. Characterization of a small PlcRregulated gene co-expressed with cereolysin O. BMC Microbiol. $7 \cdot 52$

Chaves, J. Q., C. F. Cavados, and A. M. Vivoni. 2012. Molecular and toxigenic characterization of Bacillus cereus and Bacillus thuringiensis strains isolated from commercial ground roasted coffee. J. Food Prot. 75:518-522.

Chon, J. W., J. H. Kim, S. J. Lee, J. Y. Hyeon, and K. H. Seo. 2012. Toxin profile, antibiotic resistance, and phenotypic and molecular characterization of Bacillus cereus in Sunsik. Food Microbiol. $32: 217-222$

Drobniewski, F. A. 1993. Bacillus cereus and related species. Clin. Microbiol. Rev. 6:324-338.

Ehling-Schulz, M., N. Vukov, A. Schulz, R. Shaheen, M. Andersson, E. Märtlbauer, and S. Scherer. 2005. Identification and partial characterization of the nonribosomal peptide synthetase gene responsible for cereulide production in emetic Bacillus cereus. Appl. Environ. Microbiol. 71:105-113.

FAO/WHO. 2004. Discussion paper on the proposed draft revision of the recommended international code of hygienic practice for foods for infant and children. Accessed Jan 8, 2015. ftp://ftp.fao.org/ codex/meetings/CCFH/ccfh36/fh04_11e.pdf.

Ghelardi, E., F. Celandroni, S. Salvetti, C. Barsotti, A. Baggiani, and S. Senesi. 2002. Identification and characterization of toxigenic $B a-$ cillus cereus isolates responsible for two food-poisoning outbreaks. FEMS Microbiol. Lett. 208:129-134.

Goepfert, J. M., W. M. Spira, and H. U. Kim. 1972. Bacillus cereus: Food poisoning organism. A review. J. Milk Food Technol. $35: 213-227$.

Granum, P. E., A. Andersson, C. Gayther, M. te Giffel, H. Larsen, T. Lund, and K. O'Sullivan. 1996. Evidence for a further enterotoxin complex produced by Bacillus cereus. FEMS Microbiol. Lett. 141:145-149.
Granum, P. E., and T. C. Baird-Parker. 2000. Bacillus species. Pages 1029-1039 in The Microbiological Safety and Quality of Food. B. M. Lund, T. C. Baird-Parker, and G. W. Gould, ed. Aspen Publishers, Gaithersburg, MD.

Granum, P. E., and T. Lund. 1997. Bacillus cereus and its food poisoning toxins. FEMS Microbiol. Lett. 157:223-228.

Guinebretière, M. H., V. Broussolle, and C. Nguyen-The. 2002. Enterotoxigenic profiles of food-poisoning and food-born Bacillus cereus strains. J. Clin. Microbiol. 40:3053-3056.

Hansen, B. M., and N. B. Hendriksen. 2001. Detection of enterotoxic Bacillus cereus and Bacillus thuringiensis strains by PCR analysis. Appl. Environ. Microbiol. 67:185-189.

Hansen, B. M., P. E. Høiby, G. B. Jensen, and N. B. Hendriksen. 2003. The Bacillus cereus bceT enterotoxin sequence reappraised. FEMS Microbiol. Lett. 223:21-24.

Hwang, J. Y., J. Y. Lee, and J. H. Park. 2008. Microbiological quality and potential pathogen monitoring for powdered infant formulas from the local market. Korean J. Food Sci. Anim. Resour. $28: 555-561$.

Kramer, J. M., and R. J. Gilbert. 1989. Bacillus cereus and other Bacillus species. Pages 21-70 in Foodborne Bacterial Pathogens. M. P. Doyle, ed. Marcel Dekker, New York, NY.

Kunene, N. F., J. W. Hastings, and A. von Holy. 1999. Bacterial populations associated with a sorghum-based fermented weaning cereal. Int. J. Food Microbiol. 49:75-83.

Kuo, W. S., and K. F. Chak. 1996. Identification of novel cry-type genes from Bacillus thuringiensis strains on the basis of restriction fragment length polymorphism of the PCR-amplified DNA. Appl. Environ. Microbiol. 62:1369-1377.

Lechner, S., R. Mayr, and K. P. Francis. 1998. Bacillus weihenstephanensis sp. nov. is a new psychrotolelrant species of the Bacillus cereus group. Int. J. Syst. Bacteriol. 48:1373-1382.

Lee, N., J. M. Sun, K. Y. Kwon, H. J. Kim, M. Koo, and H. S. Chun. 2012. Genetic diversity, antimicrobial resistance, and toxigenic profiles of Bacillus cereus strains isolated from Sunsik. J. Food Prot. 75:225-230.

Lindqvist, R., Y. Andersson, B. de Jong, and P. Norberg. 2000. A summary of reported foodborne disease incidents in Sweden, 1992 to 1997. J. Food Prot. 63:1315-1320.

López, A., and A. M. Alippi. 2007. Phenotypic and genotypic diversity of Bacillus cereus isolates recovered from honey. Int. J. Food Microbiol. 117:175-184.

Lund, T., M. L. De Buyser, and P. E. Granum. 2000. A new cytotoxin from Bacillus cereus that may cause necrotic enteritis. Mol. Microbiol. 38:254-261.

Lund, T., and P. E. Granum. 1997. Comparison of biological effect of the two different enterotoxin complexes isolated from three different strains of Bacillus cereus. Microbiology 143:3329-3336.

Marahiel, M. A., T. Stachelhaus, and H. D. Mootz. 1997. Modular peptide synthetase involved in nonribosomal peptide synthetase. Chem. Rev. 97:2651-2674.

Nakamura, L. K. 1998. Bacillus pseudomycoides sp. nov. Int. J. Syst. Bacteriol. 48:1031-1035.

Ngamwongsatit, P., W. Buasri, P. Pianariyanon, C. Pulsrikarn, M. Ohba, A. Assavanig, and W. Panbangred. 2008. Broad distribution of enterotoxin genes ( $h b l C D A$, nheABC, cytK, and entFM) among Bacillus thuringiensis and Bacillus cereus as shown by novel primers. Int. J. Food Microbiol. 121:352-356.

Ombui, J. N., H. Schmieger, M. M. Kagiko, and S. M. Arimi. 1997. Bacillus cereus may produce two or more diarrheal enterotoxins. FEMS Microbiol. Lett. 149:245-248.

Pirhonen, T. I., M. A. Andersson, E. L. Jääskeläinen, M. S. SalkinojaSalonen, T. Honkanen-Burzalski, and T. M. L. Johansson. 2005 Biochemical and toxic diversity of Bacillus cereus in a pasta and meat dish associated with a food-poisoning case. Food Microbiol. 22:87-91.

Rahmati, T., and R. Labbe. 2008. Levels and toxigenicity of Bacillus cereus and Clostridium perfringens from retail seafood. J. Food Prot. 71:1178-1185. 
Reyes, J. E., J. M. Bastías, M. R. Gutiérrez, and M. O. Rodríguez. 2007. Prevalence of Bacillus cereus in dried milk products used by Chilean school feeding program. Food Microbiol. 24:1-6.

Rhodehamel, E. J., and S. M. Harmon. 1995. Bacillus cereus. Chapter 14 in Bacteriological Analytical Manual, 8th ed. Food and Drug Administration, AOAC Int., Gaithersburg, MD.

Rowan, N. J., and J. G. Anderson. 1997. Maltodextrin stimulates growth of Bacillus cereus and synthesis of diarrheal enterotoxin in infant milk formulae. Appl. Environ. Microbiol. 63:1182-1184.

Rowan, N. J., G. Caldow, C. G. Gemmell, and I. S. Hunter. 2003. Production of diarrheal enterotoxins and other potential virulence factors by veterinary isolates of Bacillus species associated with nongastrointestinal infections. Appl. Environ. Microbiol. 69:2372-2376.

Schoeni, J. L., and A. C. Wong. 2005. Bacillus cereus food poisoning and its toxins. J. Food Prot. 68:636-648.

Sewell, A. M., and J. M. Farber. 2001. Foodborne outbreaks in Canada linked to produce. J. Food Prot. 64:1863-1877.

Shaheen, R., M. A. Andersson, C. Apetroaie, A. Schulz, M. EhlingSchulz, V. M. Ollilainen, and M. S. Salkinoja-Salonen. 2006. Po- tential of selected infant food formulas for production of Bacillus cereus emetic toxin, cereulide. Int. J. Food Microbiol. 107:287294.

Sivapalasingam, S., C. R. Friedman, L. Cohen, and R. V. Tauxe. 2004 Fresh produce: A growing cause of outbreaks of foodborne illness in the United States, 1973 through 1997. J. Food Prot. 67:23422353.

Stec, E. 1990. Intensity of hemolysin and lecithinase production by Bacillus cereus strains isolated from food. Rocz. Panstw. Zakl. Hig. 41:194-199.

Turnbull, P. C. B., K. Jorgensen, J. M. Kramer, R. J. Gillbert, and J. M. Parry. 1979. Severe clinical conditions associated with Bacillus cereus and the apparent involvement of exotoxins. J. Clin. Pathol. 32:289-293.

Yamada, S., E. Ohashi, N. Agata, and K. Venkateswaran. 1999. Cloning and nucleotide sequence analysis of gyrB of Bacillus cereus, $B$. thuringiensis, B. mycoides, and B. anthracis and their application to the detection of $B$. cereus in rice. Appl. Environ. Microbiol. 65:1483-1490. 